and is available from Down Brothers, Mayer by which the virus may have caused reand Phelps Ltd., Church Path, Mitcham, jection.

Surrey.-I am, etc.,

LAURENCE TINCKLER Maelor General Hospital,
Wrexham

\section{Treatment of Status Asthmaticus}

SIR,-A noteworthy point on which I differ from the opinion expressed in your commendable leading article ( 9 December, $p$. 563) is in the statement that "physiotherapy has no place in the treatment of status asthmaticus." It has been our custom during the past three years in this hospital (which is part of Helsinki University Central Hospital), in addition to other routine treatment in cases of status asthmaticus, to facilitate the patient's breathing by manual pressure on the lower part of his chest during

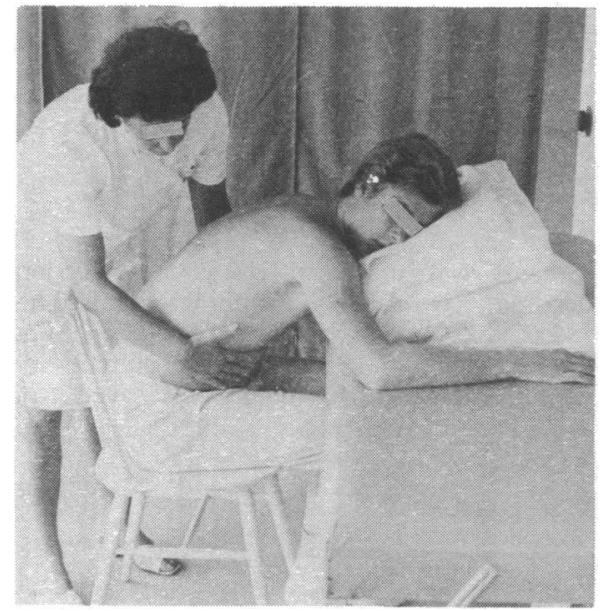

This position is the most beneficial in status asthmaticus for movement of the diaphragm if the

every expiratory phase (see fig.). Measurements (performed with a Spirostat flow meter) show that this method expels 100200 (or even 300) ml more air from the lungs than would happen spontaneously. In my opinion this respiratory help has often been decisive. It was used in 1972 in the management of 153 patients with status asthmaticus, none of whom died.

We have also diverged from the choice of drugs recommended in your article. For instance, we administer methylprednisolone intravenously instead of the hydrocortisone preparation suggested by you. This prevents retention of fluid and hypokalemia, while the antiallergic effect is at least equally good. I would like to point out, too, that ordinary adrenaline is often a more efficacious drug for asthma than beta-2-sympathomimetic preparations.-I am, etc.,

KLAus A. J. JäRVINEn

Hospital for Allergic Diseases

Helsinki, Finland

\section{Viral Infection and Renal Transplant} Rejection

SIR,-Dr. J. D. Briggs and others (2 December, p. 520) reported acute rejection of transplanted kidneys in three patients infected with influenza $A$ virus and suggested that this might be due to a generalized stimulation of the host's immune response. I should like to suggest another mechanism
Influenza $A$ virus has long been known to agglutinate erythrocytes. ${ }^{12}$ After a short time the erythrocytes separate and cannot be agglutinated a second time. This agglutination is due to the virus attaching itself to receptor sites on two different red cells and linking them together. The cell receptor sites are glycoproteins containing sialic acid, probably in a terminal position ${ }^{3}$ which is removed by a potent neuraminidase possessed by the virus, thus allowing the cells to separate once again. ${ }^{45}$ Neuraminidase-sensicells. ${ }^{6-8}$

When sialic acid is contained in an antigen it is very rarely antigenic itself. Indeed, it seems that sialic acid may serve to conceal more potent antigens and prevent them from stimulating an immune response, for treatment of many types of cell with neuraminidase has been shown to render them more highly antigenic. ${ }^{2-12}$ There is a possibility, therefore, that influenza virus may cause acute rejection of a renal transplant by removing terminal sialic acid groups from glycoprotein molecules in the renal cells and rendering them highly antigenic. If this hypothesis is correct there should be no danger of causing acute rejection by vaccinating against influenza so long as the virus is inactivated in such a way as to render it incapable of digesting sialic acid from renal cells. - I am, etc.,

W. T. MORRIS

Royal Postgraduate Medical School,

London $W .12$

1 Hirst, G. K., Science 1941, 94, 22. 3 Winzler,, 7 , 195.

Winzle, R. J., International Review of Cytology, Cohen, A. 77 in Mechanisms of Virus Infection, W. Smith. London, Academic Press, 1963. of the Society for Experimental Biology and Medicine, 1966, 122, 1255. 7 Peleq, B. A. and Ianconescu, M., Nature, 1966,

8 Pepper, D. S., and Jamieson, G. A., Nature, 9 Springer, G. F., Bacteriological Reviews, 1963, 10 Currie, 191

Currie, G. A.. and Bagshawe, K. D., British 11 Kemp, R. B., Nature, 1968, 218, i255.

Bagshawe, K. D.; and Currie, G. A., Nature,
1968, 218, 1254 .

\section{Immunological Responses in Pregnancy}

SIR,-The letter from Dr. P. Brain and others (25 November, p. 488) drew my attention to an earlier article by Dr. Ronald Finn and others (15 July, p. 150) reporting reduced $T$-cell activity during pregnancy. They found that the number of circulating $T$ lymphocytes capable of responding to stimulation with phytohaemagglutinin was reduced in pregnant women by about $10-20 \%$ and that the incidence of negative tuberculin reactions was increased by about $64 \%$.

Quite apart from the fact that some other authors have failed to find a deficiency in $T$-cells during pregnancy, 12 the depression of tuberculin reaction could perhaps be attributed to hormonal changes in the course of pregnancy. In view of the most marked increase of oestrogen production it should be mentioned that although oestrogens have been shown to depress humoral antibody responses $^{3}$ and cause involution of the thymus" there is no conclusive evidence that tive receptors have been found on other

2 Hirst, G. K. Fournal of Experimental Medicine, ${ }_{6}^{5}$ Oottschalk, A., Physiological Reviews 1957, 37, 66. they affect peripheral immunologically competent cells, ${ }^{5}$ and their effects on various cell-mediated immune reactions are rather controversial. ${ }^{6}$ The possibility should be considered, however, that reduced tuberculin reactions during pregnancy could be the result of non-specific actions of oestrogens. There is evidence that these hormones alter the physiochemical properties of the ground substances of connective tissue ${ }^{7}$ and it has been reported that they restrict the spreading of materials and fluids in the skin. ${ }^{8}$ In fact, the reduced tuberculin reaction of oestrogen-treated animals has been attributed to this mechanism rather than to depression of immunological reactivity. -I am, etc.,

St. Mary's Hospital Medical School,
London $W .2$ v. S. SIJIVIE

1 Brain, P., Marston, R., H., and Gordon, J., British Medical Fourmal, 1972, 4, 488. Gynaecology of the British Commonwealth, 1972, 79, 990 .

3 Warr, G. W., and Sljivic, V. S., Experimentia Dougherty, T. F., Physiological Reviews, 1952, Slivic, ${ }^{379}$ v. S. and Warr G. W. British fournal of Experimental Pathology, 1973. In press.
Sljivic, v. S., and Warr, G. W., Periodicum Biologorum (Zagreb), 1973. In press.

Hytten, F. E., and Leitch, 1., The Physiology of Human Pregnancy, 2nd edn. Oxford, Blackwell, 1971.

Sprunt, D. H., McDearman, S., and Raper, J.; 159.

9 Lurie, M. B., Annals of the New York Academy of Sciences, 1950, 52, 1074.

\section{Role of Pacing after Myocardial Infarction}

SIR,-The mortality figures quoted by Dr. Helen $H$. Tucker and others in their study (6 January, p. 10) seem to provide some statistical evidence that electrical pacing of patients who develop complete heart block following a myocardial infarction may, in most instances, not be necessary. In view of their findings a controlled study of the problem might appear useful, but provided the necessary skills and facilities are available, few would dispute the advantages of pacing over an isoprenaline infusion in a patient who, at that very time, is at greatest risk of developing a dangerous arrhythmia. It would be of interest to know the reasons why the authors decided to adopt the nonpacing policy in their patients.

The role of pacing in preventing ventricular arrhythmias is certainly not confined to patients with heart block. Its value in the control of recurrent ventricular tachycardia and fibrillation not responding to drug therapy is not emphasized in most reports. Although these refractory dangerous arrhythmias often denote a poor prognosis because of underlying severe myocardial damage, a very gratifying response can sometimes be achieved with a combination of pacing and antiarrhythmic drugs, as two cases recently treated at this hospital demonstrate.

The first patient, a man of 56 , suffered within a period of 24 hours from eight episodes of ventricular tachycardia, going on rapidly to ventricular fibrillation, two weeks after an extensive myocardial infarct. In spite of combined administration of all antiarrhythmic drugs available, the dangerous arrhythmias continued unabated until the intrinsic heart rate was overpaced to a rate of $120-130 / \mathrm{min}$ so that all ventricular ectopic beats could be suppressed. The pacemaker catheter was removed a week later, sinus rhythm has continued since discharge from hospital, and normal life has been resumed. 